\title{
MÍSTICA E O DIÁLOGO INTER-RELIGIOSO
}

Francilaide de Queiroz Ronsi ${ }^{1}$

Diante de uma realidade religiosa ricamente plural em que nos encontramos, somos provocados a buscar formas para que seja possibilitado o convívio harmonioso em nossa sociedade. Veremos que essa realidade provoca o Cristianismo, mais do que em outra época, a abrir-se para o reconhecimento das outras religiões em sua identidade. $\mathrm{E}$, no que diz respeito ao diálogo inter-religioso, cria condições para uma apreciação positiva das mesmas em sua pluralidade e especificidade. Procuraremos delinear uma concepção de mística a partir da experiência religiosa, na tentativa de uma compreensão mais inclusiva da realidade plural religiosa de que o outro é condição de possibilidade de viver mais profunda e radicalmente a própria fé, sem perder sua essência.

\section{O pluralismo religioso}

Nossa cultura contemporânea já nasceu plural. O pluralismo que foi gestado na modernidade chega na "pós-modernidade" ao seu auge. Logo, é claro que na situação de pluralismo religioso, inédita na história humana da forma como está acontecendo, revela-nos as próprias características desta sociedade contemporânea. (cf. MIRANDA: 1989)

Dessa forma, para essa cultura, torna-se importante passar da constatação factual da pluralidade religiosa para uma atitude de reconhecimento do valor, do significado e da riqueza das diferenças, superando tendências de dominação e desprezo, abrindo-se ao diálogo.

O que temos presenciado com o pluralismo religioso implica, para as religiões, no reconhecimento da dignidade e do direito que as pessoas possuem para viverem suas experiências de fé. Supõe uma compreensão nova da capacidade humana de captar a verdade, sempre parcial, provisória e sujeita a enriquecimento, revisão e ampliação. Nesse sentido, o Papa Francisco faz um convite para a mudança de estilo de vida no convívio com as diferenças:

"A vida é a arte do encontro, embora haja tanto desencontro na vida". Já várias vezes convidei a fazer crescer uma cultura do encontro que supere as dialéticas que colocam um contra o outro. É um estilo de vida que tende a formar aquele poliedro

1Doutora em Teologia Sistemática pela PUC-Rio e professora do Departamento de Teologia da PUC-Rio. 
que tem muitas faces, muitos lados, mas todos compõem uma unidade rica de matizes, porque "o todo é superior à parte". O poliedro representa uma sociedade onde as diferenças convivem integrando-se, enriquecendo-se e iluminando-se reciprocamente, embora isso envolva discussões e desconfianças. Na realidade, de todos se pode aprender alguma coisa, ninguém é inútil, ninguém é supérfluo. (2020: 215)

O Cristianismo é provocado a profundas mudanças, mais do que em qualquer outra época de sua história, é desafiado a abrir-se para o reconhecimento das outras religiões em sua identidade e para o diálogo inter-religioso. Oportunidade para uma 'comunicação recíproca', em 'atitude de respeito e amizade' como "conjunto de relações interreligiosas, positivas e construtivas, com pessoas e comunidades de outros credos para um conhecimento mútuo e um recíproco enriquecimento". (DIÁLOGO E ANÚNCIO: 1996) A possibilidade desse diálogo é testemunhada por homens e mulheres que, ao viverem em profundidade sua fé, com a máxima seriedade que exige a sua própria tradição, evitam uma religiosidade epidérmica, fria e indiferente aos demais.

Consequentemente, acreditamos que o mútuo reconhecimento da singularidade e das características próprias de cada tradição religiosa é condição indispensável à experiência de um diálogo inter-religioso que supera o simples reconhecimento conceitual. Além disso, cremos que a experiência de profundidade, ou seja, de mística, vivida pelos fiéis nas diferentes tradições religiosas, fundamenta a abertura ao diálogo que supera as diferenças e remete à preocupação pela melhoria e pelo progresso da humanidade.

Logo, reconhecemos a plausibilidade de semelhanças entre os místicos de diferentes tradições religiosas, sem desconhecer ou relegar o que há de único e irrevogável em cada religião. Pois é certo que o convívio com a diversidade valoriza as suas singularidades e características específicas, essenciais de cada uma em particular, e a sua irredutível alteridade.

Sim, é possível encontrar uma base para a reflexão teológica que possibilite à fé cristã o reconhecimento positivo, justo e respeitoso da pluralidade e da diversidade religiosa, sem abandonar a identidade cristã. Para isso, é preciso uma compreensão complexa e não dualista das diferenças presentes nas tradições religiosas, que possibilite o encontro e o diálogo entre as experiências de fé. Portanto, partimos da experiência 
de Deus que permitirá ao diálogo inter-religioso não se deter "nas diferenças, às vezes profundas, mas confiar-se com humildade em Deus, que é maior do que o nosso coração". (SECRETARIADO: 35)

Tomamos como referência a concepção de mística como uma experiência religiosa, na tentativa de uma compreensão mais inclusiva da realidade plural, em que a vivência de fé de um crente possibilita ao outro viver mais profunda e radicalmente a própria fé, sem perder a sua essência e identidade. Diante do nosso contexto religioso se torna, dessa forma, necessário viver com intimidade a relação com Deus, sem medo de abrir-se ao novo e, também, de aprender com o que o outro é capaz de dar. Reconhecemos que as religiões são caminhos por onde as pessoas são conduzidas à sua origem, ao que "chamamos nosso ser mais profundo, o divino em nós e em tudo o que existe". (MELLONI, 2008: 178)

\section{A mística e o diálogo}

Como vimos, diante do contexto de pluralismo religioso, a mística assume um lugar especial. Ela tem seu centro na experiência humana peculiar, que reconhece uma realidade que transcende 0 ordinário. É desse centro que as tradições religiosas encontram a sua origem e que recebe sua especificação de Mistério. Dessa especificação, segue-se a primeira peculiaridade da experiência mística em todas as suas formas, que consiste em o religioso assumir o compromisso de viver como resposta ao Mistério.

Desse modo, segundo Velasco, "é impossível, por isso, conhecer de verdade a religião sem passar pelo conhecimento da mística" (1999: 10), para que não seja ignorado o seu núcleo mais íntimo, sua verdade definitiva. Assim, a mística torna-se o caminho para avançar no conhecimento sobre a religião, porque seu estudo não vem apenas completar teoricamente o aprofundamento do fenômeno religioso, mas, sim, ser um caminho útil para avançar no conhecimento da religião e indispensável para termos um pouco de claridade diante da situação religiosa do ser humano de nossos dias.

O reconhecimento desta estreita relação é também proveniente do reconhecimento da mística como parte integrante da religião apresentado por estudos de outras ciências, como da psicologia e da filosofia. No entanto, mesmo que sejam praticamente unânimes o seu 
reconhecimento e a afirmação da presença da mística em todas as religiões, estão muito distantes a unanimidade na explicação da forma concreta da relação vigente entre os fatos e a forma precisa da presença da mística nas religiões justamente por não conseguirem esgotar o seu fenômeno. (cf. VELASCO, 1999: 31-33).

Entretanto, em toda experiência religiosa encontram-se elementos místicos e em todas as pessoas existe uma predisposição ontológica e psicológica para algo que a experiência mística assegura desenvolver em plenitude. E é, então, nesta abertura ao infinito, base do elemento místico em que se conserva a origem na presença ontológica de Deus no sujeito, que se dá o encontro pela fé.

A transformação religiosa via mística se constitui, assim, em um baluarte frente aos reducionismos antropológicos de nossa sociedade e cultura, que solicita uma transformação da religião que passe da ênfase no exterior ao interior. Tal processo provoca uma profunda mudança religiosa, advertida por religiosos e estudiosos. Porque para estes

trata-se de um passo a mais na evolução da consciência religiosa. Uma sorte da nova situação epocal religiosa, um novo 'tempo eixo', que alguns caracterizam como a fase inicial do passo da consciência mental, cognitiva, a consciência transpessoal, mística. (MARDONES, 2006: 89)

Esse giro requer um salto na consciência religiosa. Um giro para a interioridade que faça justiça à dimensão profunda da religião: a vivência da unidade com essa Realidade Última que nos envolve e que denominamos Deus.

A religião, através da história humana, sempre procurou organizar essa experiência da Transcendência e sistematizá-la em normas, rituais e conceituações doutrinais. Mas nada dessa organização poderia acontecer sem a experiência religiosa, fundamental em todas as grandes tradições religiosas, e que dá testemunho de que o ser humano é diferente de todos os seres criados, pois pode experimentar aquilo ou Aquele que o transcende e é maior do que ele ou do que se possa imaginar e conceber. (BINGEMER, 2013: 214)

Religião, neste sentido, dirá W. Jäger, é nossa condição de seres humanos, é atuar a partir da experiência de unidade de nosso ser com esta Realidade Última. (2004: 93) 
No entanto, essas experiências são revestidas de vivências muito diferentes: acontecendo na consciência da identidade com o Absoluto (brahmanismo), na extinção de si mesmo (budismo), na conformidade com a lei que rege o devir do universo (taoísmo), na féconfiança absoluta (cristianismo), na submissão incondicional (islã) etc. (cf. VELASCO, 1999: 425) Esta experiência mística em suas diferentes formas religiosas nos tem aparecido como 'vivência', na tomada de consciência, na incorporação voluntária dessa atitude fundamental que está na base de todas as religiões e que no cristianismo se chama féesperança-caridade.

Esta experiência, que não isola o religioso em seu encontro amoroso e fiel com Deus, tem como consequência um descentrar-se, um sair de si, para reconhecer o outro e, nesse reconhecimento, chegar ao Totalmente Outro.

Podemos citar, como exemplo, Thomas Merton, um monge cisterciense, considerado um dos grandes místicos do séc. $\mathrm{XX}$, que manteve um fecundo diálogo com as religiões do Oriente, profundamente ancorado em sua experiência cristã. Nele nos deparamos com uma vivência religiosa oriunda de dois inseparáveis amores: o amor a Deus e à humanidade. O seguimento de Jesus, em Merton, possui essa dupla abertura: paixão infinita por Deus, na dedicação incondicional como monge, sacerdote e eremita e no profundo amor aos humanos. Sobre o diálogo que Merton mantinha com outros religiosos, dizia que

entre essas pessoas, - se elas são fiéis ao seu chamado, à sua própria vocação, à mensagem que lhes vem de Deus, - a comunicação é possível em nível mais profundo. E o nível mais profundo de comunicação não é comunicação, é comunhão. Sem palavras. Além das palavras. Além do poder da palavra, além do conceito. Não se descobre uma nova unidade; descobre-se uma unidade antiga. Caros irmãos, nós já somos um; apenas, imaginamos não o ser. O que nos é preciso é recuperar a nossa unidade original. Temos de ser o que já somos". (MERTON, 1978: 242)

Assim sendo, em sua essência essa experiência pode se realizar de muitas maneiras e todo sujeito religioso está chamado a viver em estreita união com Deus, como assim deseja o místico. Cada pessoa pode responder a essa vocação de formas diferentes, de acordo com as múltiplas situações e circunstâncias pelas quais discorre sua vida. Visto 
que nem todos os elementos místicos se encarnam na figura histórica que até agora tem revestido e monopolizado o nome de 'místico'.

Como afirma K. Rahner, 'os místicos não representam um grau mais alto que os crentes, senão um momento interno e essencial da fé', que se realiza de formas diferentes por diferentes crentes (VELASCO, 1999: 452. Cf. nota 7). E essa fé impulsiona o sujeito à acolhida, à aceitação e ao seu reconhecimento com consciência de que esse contato o coloca diante de uma Presença 'sempre já aí'.

A experiência mística, assim, acontece por ser consequência da Revelação de Deus e da fé que move o sujeito. Por isso, a consciência religiosa, mais lúcida e desperta, pede hoje uma transformação profunda até o Mistério que a envolve e a sustenta. Dessa forma, será possível vislumbrar um larguíssimo e frutífero caminho para o diálogo, por ter sua origem na experiência que leva os seus religiosos ao mais íntimo de si, ao encontro com a Realidade Última, que se realiza na mais pura e desnuda fé amorosa, na mais absoluta confiança.

Logo, podemos entender que no diálogo inter-religioso, em que se deve evitar a indiferença e a intolerância, a mística tem um lugar privilegiado, pois, como vimos, o cultivo da dimensão mística pode ajudar a evitar esses obstáculos, já que a experiência mística permite captar o íntimo parentesco de todas as religiões ao pôr em contato quem a vive com a raiz de onde todas elas procedem: do Mistério.

Lembremos, também, o que nos afirma o Papa Francisco sobre a importância das religiões:

As várias religiões, ao partir do reconhecimento do valor de cada pessoa humana como criatura chamada a ser filho ou filha de Deus, oferecem uma preciosa contribuição para a construção da fraternidade e a defesa da justiça na sociedade. O diálogo entre pessoas de diferentes religiões não se faz apenas por diplomacia, amabilidade ou tolerância. Como ensinaram os bispos da Índia, "o objetivo do diálogo é estabelecer amizade, paz, harmonia e partilhar valores e experiências morais e espirituais num espírito de verdade e amor". (2020: 271)

Dessa forma, reafirmamos que a mística assume o melhor lugar para o encontro e o diálogo inter-religioso. Reconhecemos que, nas atuais circunstâncias, em que é indispensável o diálogo para a paz mundial, para a fraternidade humana e social, as barreiras serão superadas quando os fiéis das várias religiões estiverem abertos para a 
experiência de profundidade com o Mistério que todas elas compartilham e do qual são originárias.

\section{Para reflexão:}

1. como superar a intolerância inter-religiosa em uma sociedade marcada pelo pluralismo religioso?

2.

experiência mística pode ser considerada um lugar para o encontro e o diálogo inter-religioso? Por quê?

\section{Referências Bibliográficas}

BINGEMER, Maria C. O mistério e o mundo. Paixão por Deus em tempos de descrença. Rio de Janeiro: Rocco, 2013.

FRANCISCO, PP. Carta Encíclica Fratelli Tutti. Sobre a fraternidade e a amizade social. São Paulo: Paulus, 2020.

JÄGER, W. Adonde nos lleva nuestro anhela. La mística en el siglo XXI. Desclée, Bilbao, 2004.

MARDONES, J. Maria. Mística transreligiosa en una sociedade de incertidumbre. In:

MELLONI, Javier (org.). El no-lugar del encontro religioso. Ed. Trotta, Madri, 2008.

MERTON, Thomas. O diário da Ásia. Belo Horizonte: Ed. Veja, 1978.

MIRANDA, M. de França. Volta do sagrado: numa avaliação teológica. In: Perspectiva teológica, 21, 1989. pp. 71-83.

PONTIFÍCIO CONSELHO PARA O DIÁLOGO INTER-RELIGIOSO. Diálogo e Anúncio. São Paulo: Paulinas, 1996.

SECRETARIADO para os Não-Cristãos. A igreja e as outras religiões. São Paulo: Paulinas, 2001.

VELASCO, J. Martin. El fenómeno místico. Estudio comparado. Madri: Trotta, 1999. 